Supporting Information

\title{
Cation and Water Structure, Dynamics and Energetics in Smectite Clays: A Molecular Dynamics Study of Ca-Hectorite
}

\author{
Narasimhan Loganathan ${ }^{1}$, A. Ozgur Yazaydin ${ }^{1,2}$, Geoffrey M. Bowers ${ }^{3}$, \\ Andrey G. Kalinichev ${ }^{4}$, R. James Kirkpatrick ${ }^{5}$ \\ ${ }^{1}$ Department of Chemistry, Michigan State University, \\ East Lansing, Michigan 48824, United States \\ ${ }^{2}$ Department of Chemical Engineering, University College London, \\ London, WC1E 7JE, United Kingdom \\ ${ }^{3}$ Division of Chemistry, Alfred University, \\ Alfred, New York 14802, United States \\ ${ }^{4}$ Laboratoire SUBATECH (UMR-6457), Ecole des Mines de Nantes, \\ Nantes, F-44307, France \\ ${ }^{5}$ College of Natural Science, Michigan State University, \\ East Lansing, Michigan 48824, United States
}

Contains

Figures: 6

Discussion on H-bonding network in the interlayers and external surfaces of Ca-hectorite 


\section{Swelling Energetics}

The swelling properties of hydrated Ca-hectorite were quantitatively analyzed in terms of the basal spacings, the hydration and immersion energies, and the isosteric heats of adsorption. We used the approach introduced by Smith, ${ }^{1}$ which is widely used for the thermodynamic analysis of swelling clays. ${ }^{2-7}$ The basal spacing (equilibrium interlayer distance at a given hydration state) was calculated directly from the averages of the equilibrium NPT simulation. The immersion energy, $Q$, is defined as the energy released or adsorbed when the clay hydration is increased from one state to another by adding water to the system:

$$
Q=\langle U(N)\rangle-\left\langle U\left(N_{\text {ref }}\right)\right\rangle-\left(N-N_{\text {ref }}\right) U_{\text {bulk }}
$$

where $N_{\text {ref }}$ and $\left\langle U\left(N_{\text {ref }}\right)\right\rangle$ are the number of water molecules in the interlayer and the average internal energy of a reference hydration state. The highest water content $\left(35 \mathrm{H}_{2} \mathrm{O} / \mathrm{Ca}^{2+}\right)$ was selected to be the reference hydration state, $\left\langle U\left(N_{\text {ref }}\right)\right\rangle$, because it is the closest to that of bulk water. The energy of hydration can be defined as the energy change that occurs when a defined amount of water is added to the dry clay:

$$
\Delta U=\frac{\langle U(N)\rangle-\langle U(0)\rangle}{N},
$$

where $N$ is the number of interlayer water molecules and $\langle U(N)\rangle$ and $\langle U(0)\rangle$ are the average potential energies of equilibrated hydrated and dry clay, respectively. ${ }^{1}$ Even though both these thermodynamic quantities convey essentially the same information about clay swelling, they are related to different experimental techniques and characterize the process from slightly different perspectives. For instance, the calculated immersion energies can be directly compared with the results of calorimetric measurements. 


\section{Interlayer and Interfacial Hydrogen Bonding Structure}

The structural, energetic and dynamical properties of the $\mathrm{H}_{2} \mathrm{O}$ molecules and counter ions in the interlayer galleries and on the external surfaces of clay systems are strongly dependent on the H-bonding network formed at the clay-water interface. For Ca-hectorite, the H-bond structure on the external surface is quite different than in the mono- and bi-layer hydrates (Figure S1a-S1d). $\mathrm{H}_{2} \mathrm{O}$ molecules within $6 \AA$ of the external surfaces typically have about $3 \mathrm{H}$-bonds, and the number increases to about 3.5 at $10 \AA$ from the surface, comparable to the number in bulk SPC water seen in previous simulation studies. ${ }^{8-11}$ The minimum number of $\mathrm{H}$-bonds in the proximity-restricted region is $\sim 2.8$, and at distances $4 \AA<z<10 \AA$ the number of donated H-bonds is larger than the number of accepted H-bonds. This is because a significant fraction of the $\mathrm{H}_{2} \mathrm{O}$ molecules in this region are actively participating in the hydration shell of $\mathrm{Ca}^{2+}$ ions. At larger distances from the external surface, the numbers of donated and accepted H-bonds per molecule are, on average, equal and similar to bulk water. ${ }^{6,8,9,11-13}$

In contrast, in the interlayers of all three Ca-hectorite hydrates modeled the total number of $\mathrm{H}$-bonds per $\mathrm{H}_{2} \mathrm{O}$ molecule never exceeds $\sim 2.2$ and is often less than 2, contrasting with the average of $\sim 3$ bonds in the proximity-restricted region $(z<6 \AA)$ on the external surface. Irrespective of the hydration state, the interlayer $\mathrm{H}_{2} \mathrm{O}$ molecules located at $z<2.0 \AA$ from the basal surface (and contributing to the $\mathrm{O}_{\mathrm{H} 2 \mathrm{O}}$ ADP peaks or shoulders closest to the basal surface in Figure 3a-3c) donate $\sim 2 \mathrm{H}$-bonds to the $\mathrm{O}_{\mathrm{b}}$ (Figure $\mathrm{S} 1 \mathrm{a}-\mathrm{S} 1 \mathrm{~d}$ ), as inferred from the peak intensities in the ADPs. These molecules accept essentially no H-bonds, because they are too far from each other and the $\mathrm{H}_{2} \mathrm{O}$ molecules in the layer further from the surface that participate in $\mathrm{Ca}^{2+}$ hydration. In all three types of interlayers, $\mathrm{H}_{2} \mathrm{O}$ molecules located at $2<z<3 \AA$ on average donate $\sim 1.0 \mathrm{H}$-bond to surface $\mathrm{O}_{\mathrm{b}}$ atoms and accept and donate $\sim 0.5 \mathrm{H}$-bonds with other $\mathrm{H}_{2} \mathrm{O}$ molecules. This is similar 
to the H-bonding arrangement in the mono-layer structure of Cs-hectorite. ${ }^{14}$ In the bi-layer hydrate, $\mathrm{H}_{2} \mathrm{O}$ molecules farther than $z \approx 3.5 \AA$ from the surface do not donate $\mathrm{H}$-bonds to $\mathrm{O}_{\mathrm{b}}$ and donate and accept $\sim 0.9$ to $1.0 \mathrm{H}$-bonds to and from other $\mathrm{H}_{2} \mathrm{O}$. The absence of an H-bonding network in the interlayers that is as well-developed as on the external surface or in bulk solution contrasts with the behavior of Na-hectorite, for which the bi-layer structure has $\sim 2.9 \mathrm{H}$-bonds $\mathrm{H}_{2} \mathrm{O}$ molecule. ${ }^{5}$ For all smectites, the presence of the two basal surfaces on either side of the interlayer prevents the H-bonding from attaining a bulk like distribution, and, in the case of $\mathrm{Ca}^{2+}$, the strong coordination of the hydrating $\mathrm{H}_{2} \mathrm{O}$ molecules to the cation appears to present an additional constraint. 

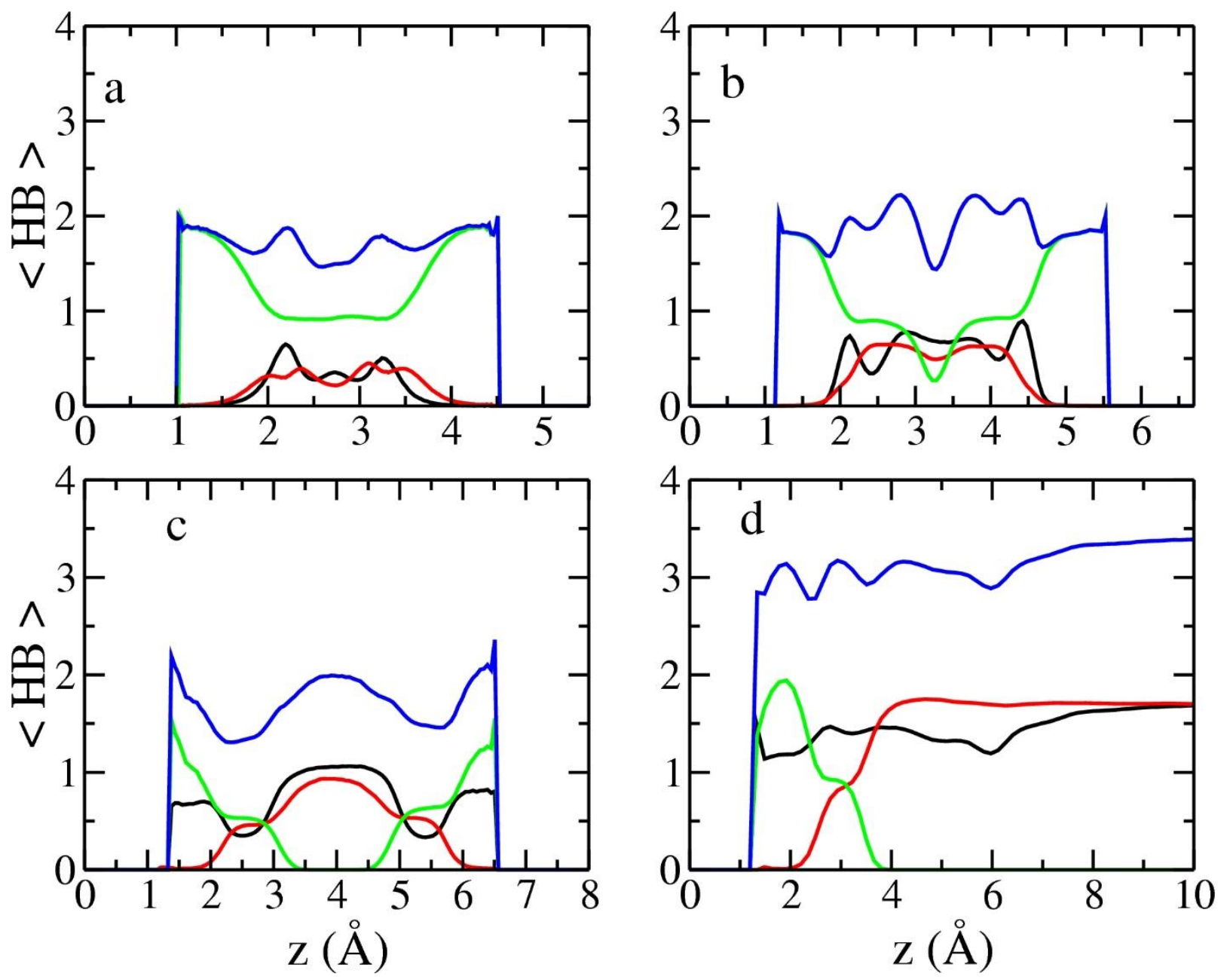

Figure S1. Calculated hydrogen bond distributions involving $\mathrm{H}_{2} \mathrm{O}$ molecules in the interlayers and on the external surfaces of Ca-hectorite as functions of distance from the basal surface. a) Partial mono-layer hydrate; b) Complete mono-layer hydrate; c) Bi-layer hydrate, d) External hectorite surface. Color code. Black - H-bonds accepted by $\mathrm{O}_{\mathrm{H} 2 \mathrm{O}}$ from $\mathrm{H}_{2} \mathrm{O}$. Red - H-bonds donated to $\mathrm{O}_{\mathrm{H} 2 \mathrm{O}}$ from $\mathrm{H}_{2} \mathrm{O}$. Green - $\mathrm{H}$-bonds donated by $\mathrm{H}_{2} \mathrm{O}$ molecules to $\mathrm{O}_{\mathrm{b}}$ surface atoms. Blue - total average number of $\mathrm{H}$-bonds experienced by one water molecule 


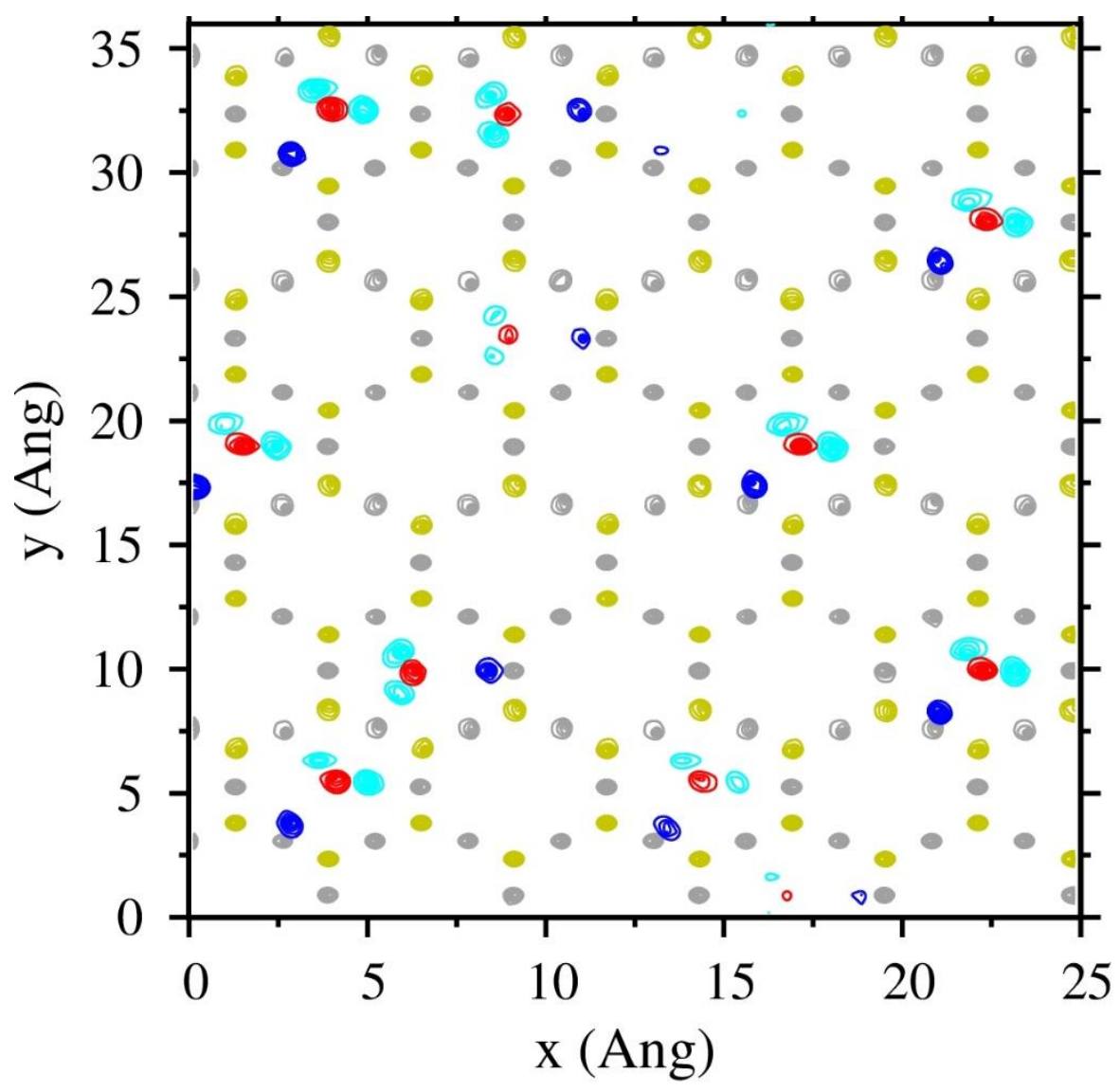

Figure S2. Calculated planar atomic density distributions (PADDs) of $\mathrm{Ca}^{2+}$ and $\mathrm{O}_{\mathrm{H} 2 \mathrm{O}}$ and $\mathrm{H}_{\mathrm{H} 2 \mathrm{O}}$ at $z<2.2 \AA$ (within the $1^{\text {st }}$ APD peak) of the partial monolayer hydrate of Ca-hectorite. Color code: $\mathrm{O}_{\mathrm{b}}$ - gray, $\mathrm{Si}$ - yellow, $\mathrm{Ca}^{2+}-$ blue, $\mathrm{O}_{\mathrm{H} 2 \mathrm{O}}-$ red, $\mathrm{H}_{\mathrm{H} 2 \mathrm{O}}-$ cyan. 


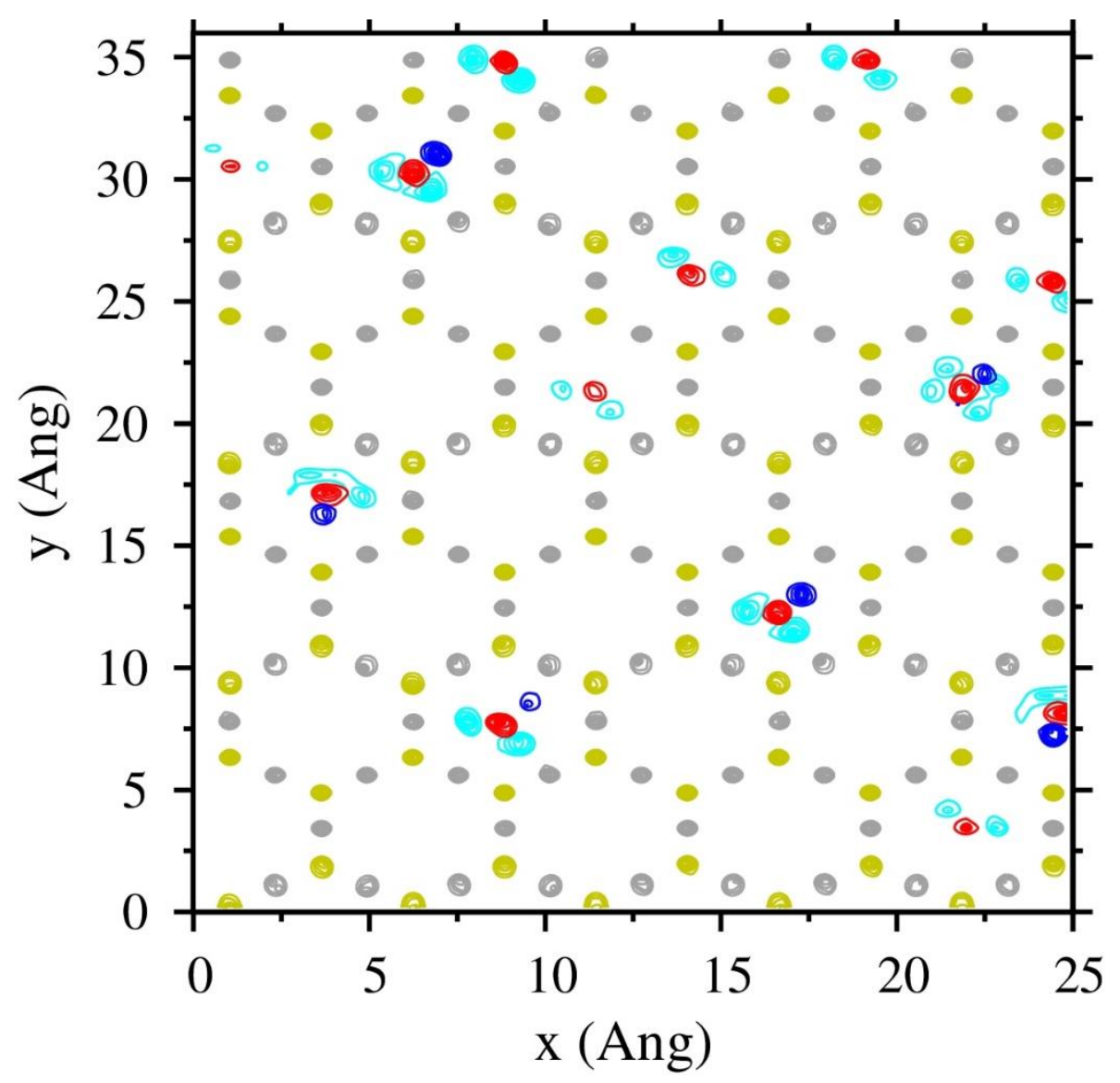

Figure S3. Calculated planar atomic density distributions (PADDs) of $\mathrm{Ca}^{2+}$ and $\mathrm{O}_{\mathrm{H} 2 \mathrm{O}}$ and $\mathrm{H}_{\mathrm{H} 2 \mathrm{O}}$ at $z<2.2 \AA$ (within the $1^{\text {st }}$ APD peak) of the complete monolayer hydrate of Cahectorite. Color code: $\mathrm{O}_{\mathrm{b}}$ - gray, $\mathrm{Si}$ - yellow, $\mathrm{Ca}^{2+}$ - blue, $\mathrm{O}_{\mathrm{H} 2 \mathrm{O}}-$ red, $\mathrm{H}_{\mathrm{H} 2 \mathrm{O}}-$ cyan. 


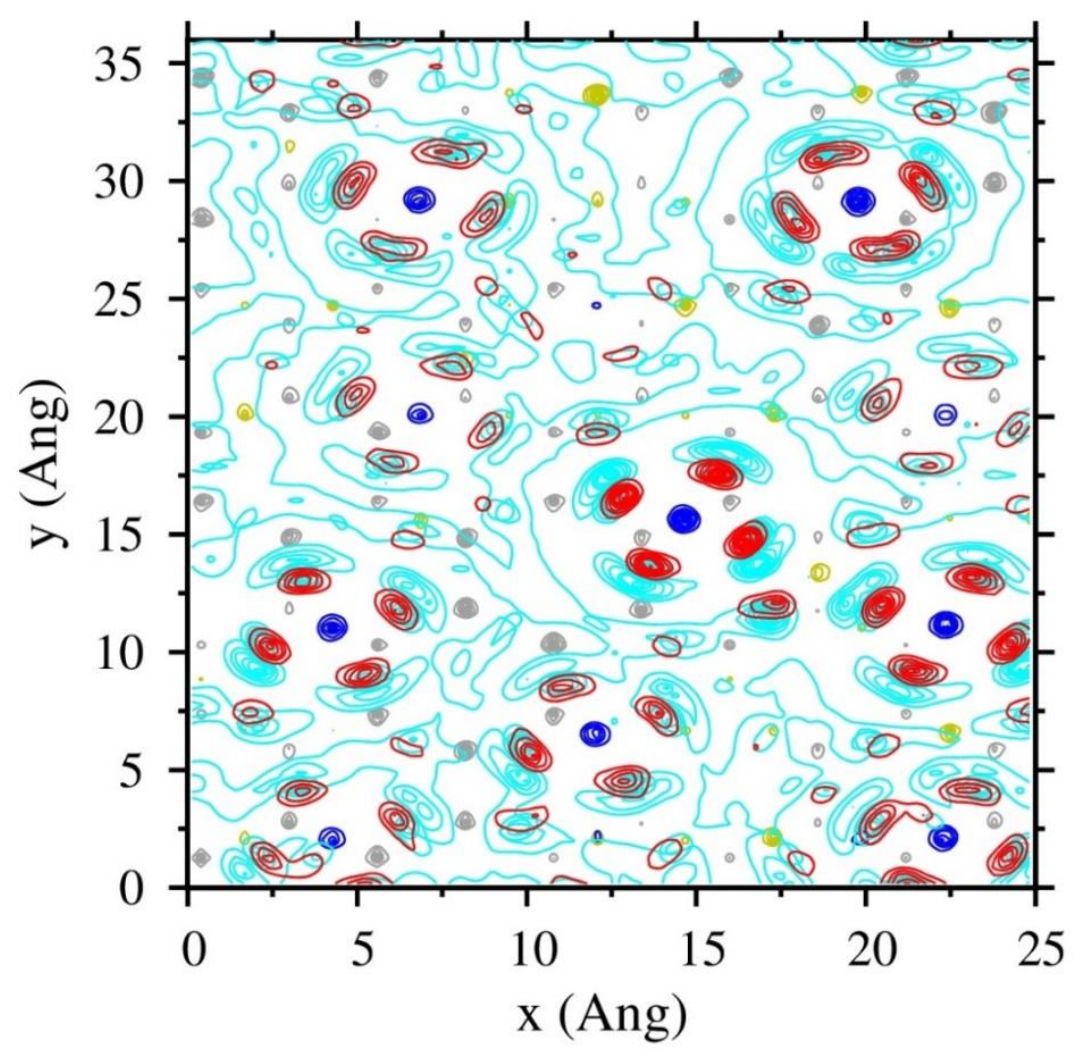

Figure S4. Calculated planar atomic density distributions (PADDs) of $\mathrm{Ca}^{2+}$ and $\mathrm{O}_{\mathrm{H} 2 \mathrm{O}}$ and $\mathrm{H}_{\mathrm{H} 2 \mathrm{O}}$ at $2.2<z<3.4 \AA$ (within the $2^{\text {nd }}$ ADP peak) in bi-layer hydrate. Color code: $\mathrm{O}_{\mathrm{b}}$ - gray, $\mathrm{Si}$ - yellow, $\mathrm{Ca}^{2+}$ - blue, $\mathrm{O}_{\mathrm{H} 2 \mathrm{O}}$ - red, $\mathrm{H}_{\mathrm{H} 2 \mathrm{O}}$ - cyan. 


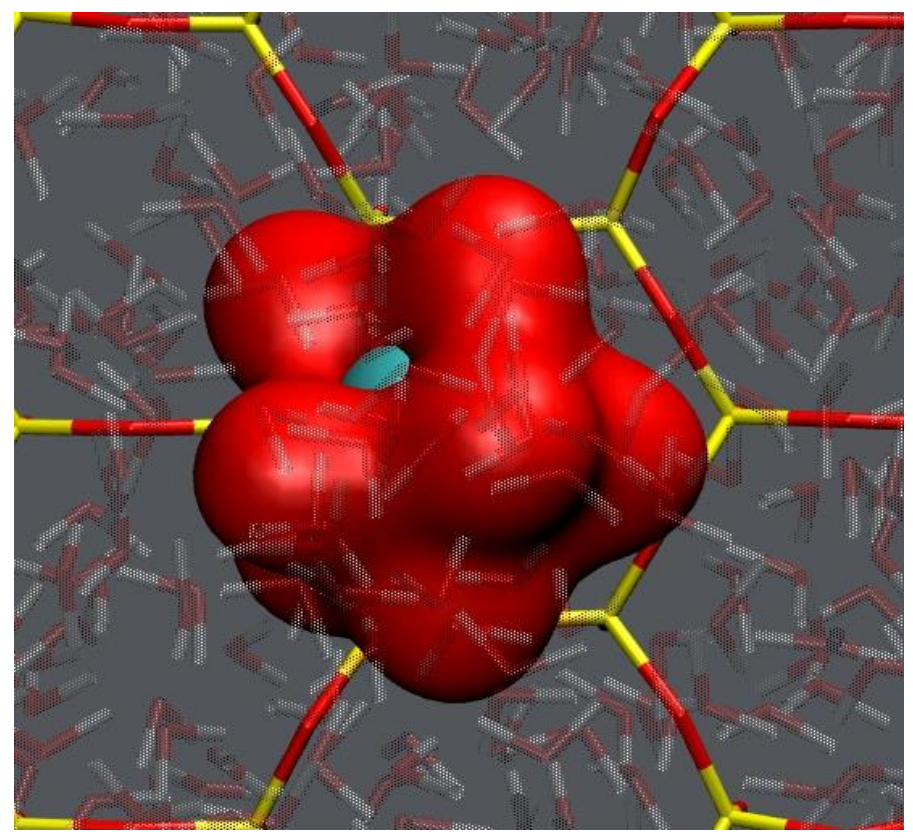

Figure S5. Pictorial representation of the nearest $\mathrm{H}_{2} \mathrm{O}$ molecules coordinating a surface $\mathrm{Ca}^{2+}$ ion on the external basal surface. (Other $\mathrm{H}_{2} \mathrm{O}$ molecules are shown in transparent color for clarity) 


\section{References}

1. Smith, D. E. Molecular Computer Simulations of the Swelling Properties and Interlayer Structure of Cesium Montmorillonite. Langmuir 1998, 14, 5959-5967.

2. Ngouana, W. B. F.; Kalinichev, A. G. Structural Arrangements of Isomorphic Substitutions in Smectites: Molecular Simulation of the Swelling Properties, Interlayer Structure and Dynamics of Hydrated Cs-Montmorillonite Revisited with New Clay Models. J. Phys. Chem. C 2014, 118, 12758-12773.

3. Liu, X.; Lu, X.; Wang, R.; Zhou, H. Effects of Layer-Charge Distribution on the Thermodynamic and Microscopic Properties of Cs-Smectite. Geochim. Cosmochim. Acta 2008, 72, 1897-1847.

4. Teich-McGoldrick, S. L.; Greathouse, J. A., Colon, C. F.; Cygan, R. T. Swelling Properties of Montmorillonite and Beidellite Clay Minerals from Molecular Simulation: Comparison of Temperature, Interlayer Cation, and Charge Location Effects. J. Phys. Chem. C 2015, 119, 20880-20891.

5. Morrow, C. P.; Yazaydin, A. O.; Krishnan, M.; Bowers, G. M.; Kalinichev, A. G.; Kirkpatrick. R. J. Structure, Energetics and Dynamics of Smectite Clay Interlayer Hydration: Molecular Dynamics and Metadynamics Investigation of Na-Hectorite. J. Phys. Chem. C 2013, 117, 5172-5187.

6. Loganathan, N.; Yazaydin, A. O.; Bowers, G. M.; Kalinichev, A. G.; Kirkpatrick, R. J. Structure, Energetics and Dynamics of $\mathrm{Cs}^{+}$and $\mathrm{H}_{2} \mathrm{O}$ in Hectorite: Molecular Dynamics Simulations with a Unconstrained Substrate Surface. J. Phys. Chem. C, DOI 10.1021/acs.jpcc.6b01016.

7. Zhang, L.; Lu, X.; Zhou, J.; Zhou, H. Hydration and Mobility of Interlayer Ions of $\left(\mathrm{Na}_{x}, \mathrm{Ca}_{y}\right)$ Montmorillonite: A Molecular Dynamics Study. J. Phys. Chem. C 2014, 118, 29811-29821.

8. Wang, J.; Kalinichev, A. G.; Kirkpatrick, R. J. Effects of substrate structure and composition on the structure, dynamics and energetics of water at mineral surfaces: A molecular dynamics modeling study. Geochim. Cosmochim. Acta 2006, 70, (3), 562-582.

9. Wang, J.; Kalinichev, A. G.; Kirkpatrick, R. J.; Cygan, R. T. Structure, energetics and dynamics of water adsorbed on the muscovite (001) surface: A molecular dynamics simulation. J. Phys. Chem B 2005, 109, 15893-15905.

10. Loganathan, N.; Kalinichev, A. G. On the hydrogen bonding structure at the aqueous interface of ammonium-substituted mica: A molecular dynamics simulation. Zeitschrift fur Naturforschung 2013, 68a, 91-100.

11. Loganathan, N.; Kalinichev, A. G. (Unpublished results)

12. Yazaydin, A. O.; Bowers, G. M.; Kirkpatrick, R. J. Molecular dynamics modeling of carbon dioxide, water and natural organic matter in Na-hectorite. Phys. Chem. Chem. Phys. 2015, 17, 23356-23367.

13. Greathouse, J. A.; Hart, D. B.; Bowers, G. M.; Kirkpatrick, R. J.; Cygan, R. T. Molecular Simulation of structure and diffusion at smectite-water interfaces: Using expanded clay interlayers as model nanopores. J. Phys. Chem. C 2015, 119, 17126-17136.

14. Malani, A.; Ayappa, K. G.; Murad, S. Adsorption isotherms of water on mica: Redistribution and film growth. J. Phys. Chem B 2009, 113, 1058-1067. 